\title{
REFUGIADOS ECONÔMICOS E A QUESTÃO DO DIREITO AO DESENVOLVIMENTO
}

\author{
Economic refugees and the right to development
}

\author{
Mônica Teresa Costa Sousa ${ }^{1}$ \\ Leonardo Valles Bento ${ }^{2}$
}

\begin{abstract}
Sumário: 1 Introdução. 2 Refugiados econômicos e a busca pelo direito ao desenvolvimento. 3 Caracterização do direito ao desenvolvimento. $4 \mathrm{~A}$ questão da titularidade e efetividade do direito ao desenvolvimento. 5 Considerações Finais. Referências.
\end{abstract}

\begin{abstract}
Resumo: O artigo tem como objetivo central destacar a preocupante situação da categoria de indivíduos reconhecida como "refugiados econômicos" e a busca dessas pessoas pela efetivação do direito ao desenvolvimento. O texto apresenta a descrição do que se compreendepor refugiados econômicos.A essa categoria, normalmente, não é estendida, de maneira imediata, a clássica proteção do Estatuto do Refugiado de 1951, mas nem por isso tais indivíduos devem ficar à margem da proteção internacional,principalmente junto a um cenário de proteção dos direitos humanos. Considerando tal fato, tem-se a definição do direito ao desenvolvimento, o que de fato buscam os indivíduos enquadrados como refugiados econômicos. Porém, na busca da concretização deste direito, deparamse com os problemas relacionados à efetivação e titularidade deles. Para elaboração deste texto, optouse pelo método dedutivo, considerando a perspectiva geral, tal seja a caracterização do status de refugiados, para a delimitação da situação dos refugiados econômicos, valendo-se para tanto de referências bibliográficas e análise documental. Conclui-se que mesmo não estando albergados pela definição clássica de refugiados, os deslocados por questões econômicas merecem a proteção destacada pelo sistema internacional de proteção dos direitos humanos.
\end{abstract}

Palavras-chave: Refugiados econômicos - Direito ao desenvolvimento - Direitos Humanos

Abstract: This article aims to highlight the worrying situation of the category of individuals informally known as "economic refugees" and the quest of these people for the realization of the right to development. The text presents the definitions of the right to development, problems related to the effectiveness and ownership of this right and also the description of what is understood today, especially in the international system of human rights, to be an economic refugees, to whom are not extended the classical protection of the 1951 Convention relating to the Status of Refugees.

Key-words: Economic Refugees - Right to development - Human Rights

\section{INTRODUÇÃO}

A movimentação internacional de pessoas não é um acontecimento recente, típico da modernidade. Desde sempre as pessoas se deslocam entre as fronteiras, pelos mais variados motivos: por necessidade econômica, para fugir de conflitos armados, porque sofrem perseguições ideológicas ou simplesmente porque querem.

E essa diversidade de motivos implica também uma diversidade de

\footnotetext{
${ }^{1}$ Doutora em Direito (UFSC). Professora dos cursos de graduação em pós-graduação em Direito da UFMA. Coordenadora do Núcleo de Estudos em Direito e Desenvolvimento (UFMA). Avaliadora do INEP/MEC.mtcostasousa@uol.com.br

2 Doutor em Direito (UFSC). Analista de Finanças e Controle da Controladoria Geral da União (CGU). Professor do curso de graduação em Direito da Unidade de Ensino Superior Dom Bosco (UNDB). vallesbento@gmail.com
} 
proteção e controle, vez que os Estados são soberanos e decidem quem pode e quem não podem permanecer no interior de suas fronteiras.

Mudar de país já foi bem mais fácil. Hoje em dia, em razão das crises econômicas e particularmente da crise do Estado de Bem Estar, muitos países adotam leis de imigração e entrada mais restritivas, esquecendo-se dos compromissos internacionalmente assumidos.

Hoje não buscam segurança em outros países apenas pessoas que fogem dos efeitos da guerra ou que buscam proteção em razão de perseguição política. Muitos indivíduos buscam a realização de seus direitos mais básicos, buscam proteção em razão de colapsos ambientais ou simplesmente buscam melhor qualidade de vida. Em todas essas situações tem-se o ser humano que merece proteção interna e que em nível internacional deve contar com um sistema de reconhecimento dos direitos humanos. Os refugiados, hoje, não são apenas aqueles enquadrados na Convenção sobre o Status de Refugiado de 1951. São também os denominados refugiados ambientais e os refugiados econômicos, esta última a categoria objeto de análise neste artigo.

Os refugiados econômicos, embora não sejam formalmente reconhecidos como refugiados, buscam a implementação e a garantia do direito ao desenvolvimento, que pode ser enquadrado como a síntese dos direitos econômicos e sociais. Considerando-se desenvolvimento como um processo que vai além da garantia de renda e de consumo, o direito ao desenvolvimento passa a ser enquadrado como direito humano, a partir da Declaração sobre o direito ao desenvolvimento, de 1986, celebrada junto à Assembleia Geral das Nações Unidas.

É certo que o mero reconhecimento internacional não é suficiente para a efetivação deste direito, e também não significa que a simples transposição de fronteiras garante ao indivíduo a concretização do direito, mas o fato é que cada vez mais pessoas estão deixando seus locais de origem simplesmente porque em tais lugares não têm oportunidades de prover os mais básicos dos direitos.

O artigo apresenta, neste contexto, a caracterização desta categoria crescente - os refugiados econômicos - e as dificuldades encontradas para sua proteção ante o sistema internacional de garantia e de reconhecimento dos direitos humanos, considerando se é ou não cabível a determinação do termo “refugiados"e se deve ou não ser aplicada a Convenção de 1951 a estes casos.

Em um segundo momento, considerando que os refugiados econômicos 
partem em busca da supressão de privações básicas, o texto se volta à caraterização do direito ao desenvolvimento, enquadrando-o como um direito humano e desta forma tomando parte no sistema internacional de proteção destes direitos.

Por fim, volta-se o texto às problemáticas encontradas para efetivação e garantia do direito ao desenvolvimento, passando pela dificuldade de reconhecimento formal em âmbito interno bem como pela questão da titularidade do mesmo. Conclui-se, ao final que mesmo não estando albergados pela definição clássica de refugiados, os deslocados por questões econômicas merecem a proteção destacada pelo sistema internacional de proteção dos direitos humanos.

\section{REFUgIAdos ECONÔMICOS E A BUSCA PELO DIREITO AO DESENVOLVIMENTO}

Não é atual a problemática envolvendo a movimentação internacional de pessoas. Os grandes fluxos migratórios ocorrem há séculos, com momentos de maior ou menor intensidade. Em períodos marcados por conflitos armados internacionais, como as duas Grandes Guerras Mundiais, certamente há uma intensificação do fluxo de pessoas. O mesmo se pode dizer em razão dos conflitos armados que não alcançam proporções internacionais, como as guerras civis, mas que infelizmente são capazes de levar um grande número de pessoas a deixar seus países de origem em busca de segurança.

Considerando esta situação, desde a década de 1950 tem-se um documento internacional reconhecido e apto a atender, de maneira razoavelmente satisfatória, as pessoas que se encontram em situações limite de perseguição, caracterizando-se como refugiados. De acordo com o Estatuto do Refugiado, pode ser definido como tal aquele que está fora de seu país ou que não pode recorrer à proteção dele em razão do fundado temor de perseguição por motivos de raça, religião, nacionalidade, por pertencer a um determinado grupo social ou por razões políticas (art. $1^{0}$ ).

Esta definição,entretanto, não é suficiente para enquadrar as diversas categorias de pessoas que atualmente deixam seus países de origem, não apenas pelo temor de perseguição política, mas também por motivos outros que se relacionam diretamente com a questão dos direitos humanos. Considerando que eles são indissociáveis, não se trata apenas da garantia dos direitos humanos de primeira dimensão (direitos civis e políticos), estes perfeitamente enquadrados na definição estabelecida pela Convenção de 1951, mas também se apresentam hoje problemas 
relacionados ao fluxo de pessoas sem perspectiva de garantia dos direitos de segunda dimensão, tais sejam direitos econômicos, sociais e culturais, bem como os direitos de terceira e quarta dimensão, dentre eles o direito ao desenvolvimento.

Justamente neste ponto reside a grande problemática: a identificação e o reconhecimento, ainda que não de maneira formal, de novas categorias de refugiados, tais sejam os refugiados ambientais e os refugiados econômicos, sendo que sobre esta última categoria versa especificamente este trabalho. Quanto aos refugiados ambientais, podem ser definidos nas palavras de El-Hinnawi:

[...] pessoas forçadas a deixar seu habitat natural, temporária ou permanentemente, por causa de uma marcante perturbação ambiental (natural e/ou desencadeada pela ação humana), que colocou em risco sua existência e/ou seriamente afetou sua qualidade de vida. Por "perturbação ambiental", nessa definição, entendemos quaisquer mudanças físicas, químicas, e/ou biológicas no ecossistema (ou na base de recursos), que o tornem, temporária ou permanentemente, impróprio para sustentar a vida humana $(1985$, p. 04-05).

Para esta identificação, faz-se necessário em um primeiro momento estabelecer a diferença entre o migrante econômico e o refugiado, fundamental para se determinar inclusive se a Convenção de 1951 e os demais instrumentos de proteção aos refugiados podem incidir sobre a categoria dos refugiados econômicos.

Com o crescimento da população mundial e a relativa facilidade de deslocamento populacional, cada vez é maior o número de pessoas que deixam seus países de origem em busca de melhores condições de vida, principalmente a partir da divulgação de indicadores como o Índice de Desenvolvimento Humano (IDH), que faz com que pessoas originárias de países com baixo IDH migrem para países de IDH mais elevado, nos quais se espera uma melhor qualidade de serviços de saúde, educação e maiores oportunidades de obtenção de renda, considerando-se os indicadores básicos componentes do Índice de Desenvolvimento Humano, tais sejam renda, educação e longevidade.

Fatores como a crise econômica, principalmente nos países da Europa ocidental, entretanto, têm feito com que estesEstados endureçam a política migratória, tornando cada vez mais difícil a migração e a oportunidade de regularização da situação das pessoas que cada vez mais procuram esses países, vindos principalmente de países africanos. Ainda que a África esteja assolada por conflitos civis e muitas pessoas realmente deixam os países deste continente em razão destes embates, é cada vez maior o número de indivíduos que, em grupos ou isoladamente, buscam nos países da Europa a realização dos direitos humanos mais 
básicos.

Para Erika Feller (2011, p.15), estas pessoas travam uma "luta diária por legitimidade, para estabelecer uma residência legal, para se mover livremente, para emprego, para ter acesso à assistência médica e educação para os filhos”.

De acordo com o ACNUR hoje mais de 43 milhões de pessoas ao redor do mundo podem ser enquadrados como "deslocados forçados", sem que necessariamente o sejam em razão de conflitos armados ou perseguições políticas (ACNUR, 2013), e cada vez mais a Convenção de 1951 se torna um instrumento inadequado para lidar com todos os casos que envolvem o fluxo internacional de pessoas.

Considerando este fato, tem-se, em um primeiro momento, a distinção entre o grupo diretamente beneficiado pela Convenção de 195, tal seja o grupo representado pelos refugiados de guerra e os refugiados políticos, o grupo representado pelos migrantes econômicos e o grupo representado pelos refugiados econômicos.

Em relação ao primeiro, a definição já foi apresentada e este grupo é abrangido pela Convenção. Já os migrantes econômicos se caracterizam pela voluntariedade. Este migrante, no dizer de Casella(2001), poderia ao menos em tese, subsistir em seu país de origem. Mas diante da insatisfação com as condições locais, se desloca para outro país, em busca de melhores condições de vida. Neste caso, observa-se que outros dispositivos internacionais são cabíveis para a sua proteção, como a Convenção Internacional sobre a Proteção dos Direitos de Todos os Trabalhadores Migrantes e dos Membros das suas Famílias, adotadapela Resolução 45/158, de 18/12/1990, da Assembleia-Geral das Nações Unidas.

Em um outro quadro estão inseridos os "refugiados econômicos”, forçados a deixar seus países de origem pela total impossibilidade de satisfazer suas necessidades vitais básicas. O refugiado econômico é, nas palavras de Cunha (2008, p. 192), movido pelo instinto de sobrevivência. Apesar de não reconhecidos como uma "categoria" oficial de refugiados, os refugiados econômicos não podem como já sinalizado, ficar à margem do sistema internacional de proteção à pessoa humana.

Keller (2011) destaca as hipóteses de cabimento ou não da Convenção de 1951 e dentre estas situa a questão das migrações com finalidade econômica. Para a autora, há quatro hipóteses para sustentar ou não a aplicabilidade da convenção. Em um primeiro momento, estão os refugiados por motivos de perseguição e violência 
direcionada, enquadrados de maneira natural no art. $1^{\circ}$. Neste caso, a Convenção de 1951 é cabível e relevante. Logo após, Keller destaca os fluxos migratórios em larga escala, envolvendo supostos refugiados; neste caso, a Convenção é uma aspiração e pode ser aplicada.

Em outro quadro, a autora situa as pessoas que se deslocam forçosamente, mas por um motivo diferenciado da perseguição política ou violência, e destaca que a Convenção de 51 não deveria ser aplicada, cabendo aqui um modelo distinto de proteção. Podem ser enquadrados os refugiados ambientais. A fim de ilustrar esta situação, Keller (2011, p. 23) aponta que "[...] pessoas são deslocadas para além de suas fronteiras em uma combinação de fatores que as deixam muito vulneráveis ou que exacerbem vulnerabilidades a tal ponto que fugir torna-se mais viável que permanecer".

Por fim, têm-se os fluxos migratórios mistos que incluem migrantes em sentido clássico. Fluxos mistos incluem não apenas migrantes no sentido clássico, mas também pessoas com necessidades imediatas. Nesta questão, a Convenção verdadeiramente não se aplica. Nunca houve a intenção, por parte do ACNUR e da própria Convenção, de abordar essa questão por meio de mecanismos de proteção de refugiados. Sobre esta aparente lacuna da Convenção de 1951, Keller (2011, p. 27) argumenta: "Essa não é uma falha da Convenção, e esta não pode ser responsabilizada pela incapacidade dos Estados de lidar de maneira efetiva com a migração em massa”.

Sobre esta não aplicabilidade, Cunha (2008) destaca que o sistema internacional de proteção aos refugiados não pode ser imediatamente aplicado aos migrantes em sentido amplo, sob pena de erosão do sistema. Além disso, a Convenção de 51 foi elaborada, como já ressaltado, em um contexto de proteção imediata aos direitos de primeira dimensão, o que não afasta, em absoluto, a necessidade de se estender todos os mecanismos de proteção internacional dos direitos humanos às demais categorias, como os refugiados ambientais e os refugiados econômicos, considerando principalmente a indivisibilidade que marca os direitos humanos.

Justamente em razão dessa indivisibilidade é que os direitos econômicos e sociais não podem passar ao largo do sistema internacional de proteção à pessoa humana. Pessoas que se deslocam em razão da falta grave de efetividade dos direitos econômicos e sociais precisam de proteção internacional, mas muito se questiona 
sobre o alcance desta proteção, vez que envolve questões como a que segue. Até que ponto um país deve abrir suas fronteiras a pessoas fugindo de uma situação causada pela ineficiência de seus próprios Estados? Ou ainda, qual tipo de ajuda ou proteção o Estado estrangeiro deve prover?

Estas questões continuam sem resposta, e muitas vezes é mais fácil e até mesmo compreensível que o país de destino se negue a recebe-las, seja em razão da sua própria incapacidade econômica, seja por pressão de seus nacionais, afinal, como sinalam Jubilut e Apolinario (2011, p. 289), a violação de direitos econômicos e sociais ocorre mais por negligência que por meio de um ato formal ou ações específicas de um agente perseguidor. Apesar de reconhecer as dificuldades em separar a situação de um indivíduo das condições gerais de seu país, as autoras alertam para um caso em que se pode caracterizar a perseguição ou o ato formal: É quando a ausência de condições de efetivação dos direitos econômicos e/ou sociais é direcionada a um determinado grupo ou categoria, como acontece com os ciganos, como se vê:

O dilema dos direitos econômicos, sociais e culturais encontra-se no fato de que, se um Estado falha em prover tais direitos para toda a população por meio de políticas e programas, é difícil argumentar casos individuais, alegando que tais direitos não são realizados. O que se pode argumentar é que, em razão de suas opiniões políticas, sua etnia, ou de pertencimento a algum grupo social, esses indivíduos são privados por um agente - o Estado ou outra entidade com poder suficiente - de trabalhar, de receber educação ou tratamento de saúde. O ponto crucial é que o Estado, ou outro agente atua contra o indivíduo, e isso constitui uma perseguição (2011, p. 289).

Portanto, ao se considerar a vulnerabilidade de determinados grupos ou categorias em relação aos direitos econômicos e sociais, há como enquadrá-los no sistema clássico de proteção ao refugiado, vez que há uma ação dirigida. Porém, a dificuldade se perpetua se as condições precárias de efetivação dos direitos econômicos e sociais são genéricas em determinado território.

O que se tem, quando da generalização da precariedade da efetivação dos direitos de segunda, terceira e quarta dimensões é justamente a não garantia do direito ao desenvolvimento, considerado este como um processo de expansão das capacidades e supressão de privações. E no dizer de Jubilut e Apolinário (2011, p. 290), “[...] indivíduos aos quais é negado o direito ao desenvolvimento, consoante a Declaração sobre o Direito ao Desenvolvimento (1986) continuam sem proteção internacional".

Os refugiados econômicos se enquadram exatamente nesta situação, quadro que pode ser agravado nos casos em que há ausência de instituições 
democráticas e elevado grau de pobreza, como em muitos países da África sub saariana. Estas situações podem levar a uma situação insustentável para os indivíduos, cumulando elevados índices de mortalidade infantil com alta desnutrição, fomes coletivas e analfabetismo, chegando-se a situação apontada pelo Relatório de Desenvolvimento Humano de 1990 (UNDP, 2013), ao determinar que o indivíduo estar condenado pelo lugar de nascimento.

Sobre tal situação, Jubilut e Apolinário (2011, p. 290) destacam:

[...] pode-se buscar por meio da cooperação internacional reverter o quadro de desenvolvimento do Estado - todavia, isso demanda longo prazo -; ou se pode tentar diferenciar mesmo, entre as situações de ausência de desenvolvimento, aquelas que resultam em pessoas as quais demandam proteção internacional, visto que o futuro certo com fome e doenças configura sim fator externo que compele o indivíduo à migração, mesmo não havendo uma perseguição configurada.

O que se verifica, portanto, é que há categorias de pessoas que não se enquadram na situação típica de refugiados, mas mesmo assim precisam de proteção internacional vez que em seus países de origem não há condições de vida digna. Nestes casos, o que estas pessoas buscam nada mais é que a efetivação da síntese dos direitos humanos, tal seja o direito ao desenvolvimento. Porém, o reconhecimento e a efetivação deste direito passam por questões delicadas, como se vê a seguir.

\section{CARACTERIZAÇÃO DO DIREITO AO DESENVOLVIMENTO}

Desde a criação das Nações Unidas que a questão do desenvolvimento e das diferenças econômicas e sociais entre os países têm sido ponto de discussão. Ainda que a temática do desenvolvimento tenha sido tratada por algum tempo em instâncias diferentes, as Nações Unidas elaboraram uma série de Resoluções a respeito, e uma delas, em especial, se volta para um componente fundamental do arcabouço normativo de proteção dos direitos humanos, a Declaração sobre o Direito ao Desenvolvimento de 1986, aprovada na forma da Resolução A/RES/41/128, de 4 de dezembro de 1986, com oito abstenções (Dinamarca, Finlândia, Islândia, Israel, Japão, Reino Unido, Suécia e República Federal da Alemanha) e o voto contrário dos Estados Unidos (UN, 2007).

O conceito de desenvolvimento tinha, até a década de 1990, um forte viés economicista. Desenvolvimento era visto tão somente como crescimento econômico. Daí algumas instâncias na ONU terem se dedicado ao tema de maneira limitada. A partir da década de 90, com a divulgação dos Relatórios de Desenvolvimento Humano e dos Índices de Desenvolvimento Humano, a ONU se 
volta, de maneira global, ao desenvolvimento não mais como crescimento econômico, mas sim como desenvolvimento humano, levando em consideração fatores como renda, educação, saúde, liberdades políticas e garantias sociais.

A Declaração sofre críticas por ser considerada pouco eficaz no sentido de apresentar compromissos internacionais gerais exigíveis, mas sem previsão de sanção em caso de descumprimento destes acertos. Porém, é importante não apenas por reconhecer definitivamente o direito ao desenvolvimento como um direito humano, ressaltando o caráter universal e indivisível desta classe de direitos, mas também por estabelecer as dimensões coletiva, individual, internacional e interna do direito ao desenvolvimento.

Embora a questão da obrigatoriedade das Resoluções das organizações internacionais seja complexa e controversa, é inegável que a Declaração sobre o Direito ao Desenvolvimento de 1986 inspira a observância e a codificação do direito ao desenvolvimento em âmbito internacional e interno. Na esfera internacional, outras normas e convenções trataram do tema especificamente a partir das disposições trazidas pela Declaração de 86, como a Declaração e Programa de Ação de Viena de 1993 e o Consenso de Monterrey em 2002.

O Consenso de Monterrey foi adotado pelos Chefes de Estado como documento final da Conferência Internacional para Financiamento do Desenvolvimento, realizada na cidade de Monterrey, México, em março de 2002. Ressaltava a preocupação global com a questão da desigualdade, reconhecendo que o financiamento para as ações de promoção do desenvolvimento deveria se dar de maneira individualizada, variando de país a país, levando-se em consideração a necessidade específica de cada Estado. As recomendações do Consenso de Monterrey se fundamentavam em três pilares principais: i) fortalecimento da democracia; ii) boa governança econômica e iii) reforço de valores morais e jurídicos (FRIED, 2004, p. 12). Sachs (2005, p. 217-218) também destaca o Consenso de Monterrey como uma das mais importantes conferências realizadas após o início da Rodada Doha para o Desenvolvimento da OMC.

Em âmbito interno, algumas Constituições se voltaram para a previsão de questões relacionadas ao direito ao desenvolvimento, como é o caso da Constituição Federal de 1988, que desde seu preâmbulo determina que o Estado democrático 
instituído é destinado a assegurar o desenvolvimento da sociedade3; estes exemplos reforçam o entendimento acerca da Declaração sobre o Direito ao Desenvolvimento como marco mais significativo, na ordem normativa internacional, quanto ao reconhecimento deste direito.

Disposta em um longo preâmbulo e 10 artigos, a Declaração de 1986 acomoda as preocupações dos países desenvolvidos sem deixar de lado os requerimentos dos países em desenvolvimento, e justamente por este aspecto um tanto diplomático verifica-se a opção de não enfrentar questões que permanecem complexas até os dias atuais, como a questão da efetivação do direito ao desenvolvimento. Mas nem por isso a Declaração perde importância; ao contrário, é a Declaração de 1986 que cristaliza de forma mais contundente a preocupação da sociedade internacional com a questão do desenvolvimento, deixando de lado polaridades econômicas levantadas pelas discussões quando da determinação na Nova Ordem Econômica Internacional. A Declaração determina em seu art. $1^{0}$ o ser humano como essencial no processo de desenvolvimento, seu principal participante e beneficiário e para tanto é essencial a garantia e efetivação do seu conjunto de direitos humanos, inclusive do direito ao desenvolvimento, reconhecido pelo texto como um direito humano inalienável.

No extenso preâmbulo da Declaração, as Nações Unidas reconhecem que desenvolvimento é um processo econômico, social, cultural e político que busca o bem-estar de todos os indivíduos a partir de sua participação ativa e livre no desenvolvimento e na distribuição dos benefícios alcançados neste processo.

A Declaração de 1986 reforça o papel do indivíduo como sujeito central no processo de desenvolvimento ao mesmo tempo em que permite que o ser humano deixe de ser visto como mero fator de produção. O indivíduo é determinante no processo de desenvolvimento não por sua utilidade ao longo do processo, mas muito principalmente por ser o sujeito determinante do mesmo (DELGADO, 2001, p. 92).

Outro ponto que é destaque no preâmbulo da Declaração é o reconhecimento de obstáculos ao processo de desenvolvimento, dentre estes a negação dos direitos humanos; a Declaração de 1986 reforça o caráter indivisível e

3Sobre o desenvolvimento na Constituição de 1988: LOCATELLI, Liliana. Desenvolvimento na Constituição Federal de 1988. In: BARRAL, Welber (Org.). Direito e desenvolvimento: análise da ordem jurídica brasileira sob a ótica do desenvolvimento. São Paulo: Singular, 2005, p. 95-118; SILVA, Guilherme Amorim Campos da.Direito ao desenvolvimento. São Paulo: Método, 2004. 
interdependente dos direitos humanos, considerando que todas as categorias destes direitos devem ser implementadas, promovidas e protegidas sem distinção, reforçando o entendimento de que o respeito e a garantia de determinados direitos humanos não podem justificar a negação de outros. As questões mais controversas previstas na Declaração sobre o Direito ao Desenvolvimento de 1986 assim o são porque o texto estabelece responsabilidades e prerrogativas, mas não esclarece como essas serão exercidas, ou seja, falta à Declaração de 1986 a previsão de um mecanismo de enforcement.

A Declaração de 1986 pode parecer retórica e até mesmo repetitiva, mas é importante principalmente na caracterização do direito ao desenvolvimento como um direito humano. Além disso, a Declaração deixa claro o que talvez seria um novo leitmotiv para as Nações Unidas: a redução das desigualdades e da pobreza, objetivos centrais também do processo de desenvolvimento.

A Declaração afasta a ideia economicista que vincula desenvolvimento a crescimento econômico e não retoma temas que foram exaustivamente tratados pelas resoluções anteriores à Declaração como relacionados ao desenvolvimento (comércio internacional, transferência de recursos econômicos, constituição de fundos econômicos internacionais para promoção do desenvolvimento). Não que tais temas devam ser afastados do processo, mas não constituem mais a única hipótese de promoção do desenvolvimento. A Declaração não apenas confirma o direito ao desenvolvimento como direito humano; estabelece que o desenvolvimento é um processo em que todos os direitos humanos devem ser garantidos e realizados.

A Declaração sobre o Direito ao Desenvolvimento não afasta o caráter indissociável e interdependente dos direitos humanos. Considera o desenvolvimento um processo social, econômico, cultural e político, portanto, não há porque tratar o direito ao desenvolvimento como um direito humano diferenciado dos demais. A leitura isolada da Declaração de 1986 pode parecer suficiente para a compreensão do conteúdo e dos objetivos do direito ao desenvolvimento, mas é em conjunto com o ordenamento internacional garantidor dos direitos humanos que salta aos olhos a coerência e o cabimento deste direito juntamente com outras obrigações internacionais assumidas.

Desde a Carta das Nações Unidas, passando pela Declaração Universal dos Direitos Humanos, pelo Pacto sobre Direitos Civis e Políticos, pelo Pacto sobre Direitos Econômicos, Sociais e Culturais, pela Carta de Direitos e Deveres 
Econômicos dos Estados e pela Declaração e Programa de Ação de Viena de 1993 que o sistema internacional de proteção e de garantia dos direitos humanos caminha de maneira idêntica. Há necessidade de cooperação internacional a partir de Estados, organizações internacionais, indivíduos e organizações sociais a fim de promover o desenvolvimento como processo de garantia dos direitos humanos e igualdade de oportunidades.

Em verdade, o Direito Internacional vem se desenvolvendo no sentido de criar para os Estados obrigações exigíveis com o intuito de adotar políticas e programas capazes de garantir bem-estar econômico, social e cultural ainda que em níveis mínimos (TRUBEK, 1984, p. 207). De uma maneira ou de outra estes instrumentos normativos indicados se voltam para estes objetivos.

A partir de 1993, quase todos os órgãos e programas das Nações Unidas apresentam determinações específicas sobre a promoção do direito ao desenvolvimento e dos direitos humanos. Na verdade, o reconhecimento do direito ao desenvolvimento como um direito humano é responsável pela renovação desta temática junto aos organismos das Nações Unidas, que promoveram a partir desta integração ações interdisciplinares e relacionadas.

O Banco Mundial, por exemplo, reconhece especificamente que ao promover programas relacionados ao desenvolvimento, o objetivo central é o de criar condições, principalmente a partir dos projetos financiados pela instituição, para que os indivíduos possam efetivamente dispor dos direitos humanos (WORLD BANK, 1998).

De maneira geral projetos financiados pelo Banco Mundial estão associados mesmo indiretamente, às questões relacionadas aos direitos humanos, como os que tratam especificamente de redução da pobreza, investimentos em projetos de saúde e educação, crescimento econômico e aumento de renda, iniciativas voltadas exclusivamente para os países em desenvolvimento e a redução de suas dívidas externas, ações voltadas para implementação de mecanismos de boa governança e combate à corrupção, financiamentos de programas de acesso ao crédito e à justiça, programas de capacitação para as mulheres em países com problemas de desigualdade de gênero acentuada e programas de redução de trabalho infantil (WORLD BANK, 1998, p.14).

Reconhecer o direito ao desenvolvimento como um direito humano é determinante também para o trabalho do PNUD, que alia ao seu objetivo central a 
promoção e a proteção dos direitos humanos. Em relação à promoção dos direitos humanos, as principais determinações do PNUD dizem respeito: i) ao apoio institucional às políticas nacionais de desenvolvimento; ii) a efetivação de estratégias de aproximação de tais políticas com a questão dos direitos humanos (humanrightsbased approach); iii) a assistência institucional às iniciativas locais de promoção dos direitos humanos que envolvam a conscientização da sociedade civil para esta questão; e iv) apoio às iniciativas de criação de instituições locais voltadas para os direitos humanos (UNDP, 2007).

Não apenas o Banco Mundial e o PNUD, mas também outros organismos e programas das Nações Unidas direta ou indiretamente voltam-se para o direito ao desenvolvimento uma vez que procuram sempre afirmar o compromisso da organização com a questão dos direitos humanos, afastando a tendência de deixar este assunto para os órgãos especializados.

Há no sistema da ONU pelo menos um órgão dedicado exclusivamente aos direitos humanos: o Conselho de Direitos Humanos, presidido pelo Alto Comissário das Nações Unidas para Direitos Humanos. O Conselho foi estabelecido pela A/RES/60/251, de 03 de abril de 2006 e substitui a antiga Comissão de Direitos Humanos. Há ainda seis órgãos criados em virtude dos tratados de direitos humanos que supervisionam a implementação dos tratados de direitos humanos: i)omitê de Direitos Econômicos, Sociais e Culturais; ii) Comitê para a Eliminação da Discriminação Racial; iii) Comitê para a Eliminação da Discriminação contra a Mulher; iv) Comitê contra a Tortura; v) Comitê dos Direitos da Criança; vi) Comitê para a Proteção dos Direitos de todos os Trabalhadores Migrantes e de seus Familiares.

Neste ponto o direito ao desenvolvimento desempenha um papel fundamental: ao se estabelecer como meta deste ou daquele programa ou agência a promoção dos direitos humanos, as Nações Unidas buscam também a garantia do direito ao desenvolvimento, vez que o reconhecimento dos direitos humanos é um primeiro passo na concretização do processo de desenvolvimento proposto pela organização.

Em sendo o direito ao desenvolvimento um direito humano, ou seja, atribuindo-lhe as mesmas garantias e valorações que são atribuídas aos direitos civis e políticos, econômicos, sociais e culturais, não há porque desconsiderar o direito ao desenvolvimento dos programas relacionados aos direitos humanos. 
Em razão da universalidade e da indivisibilidade dos direitos humanos, o direito ao desenvolvimento acarreta não apenas no plano normativo, mas também no plano operacional, obrigações erga omnes, e, desta forma é essencial a efetivação de normas internas e internacionais voltadas para o combate de abusos econômicos vinculados "à concentração e às práticas comerciais restritivas, através de instrumentos que permitam a transparência do mercado, assim como a correção de suas deficiências" (PERRONE-MOISÉS, 1998, p. 56).

Reconhecido como inalienável e integrante de toda a sistemática internacional relacionada aos direitos humanos, o direito ao desenvolvimento é um direito do indivíduo e dos Estados, de caráter global e multidimensional, de acordo com o Preâmbulo e o art. $1^{\circ}$ da Declaração de 1986, o que significa dizer que há mais de um componente na definição do objeto do direito ao desenvolvimento, considerando-se as dimensões civil, política, econômica e social dos direitos humanos.

A principal consequência do reconhecimento do direito ao desenvolvimento como um direito humano é a desvinculação do conceito de desenvolvimento de seu viés exclusivamente economicista, na medida em que ações e programas internacionais aproximam o conceito de desenvolvimento de dimensões sociais mais próximas da temática dos direitos humanos que das relações econômicas internacionais.

No entender de Perrone-Moisés (1998, p. 57), deve-se buscar uma visão humanista de desenvolvimento, afastando-se a sociedade internacional de uma perspectiva exclusivamente econômica. Certamente a ideia que melhor atende a esta proposta é a que determina o desenvolvimento como componente do conjunto dos direitos humanos, levando-se em consideração todas as garantias (e dificuldades) que a tais direitos estão associadas.

Confirmar o direito ao desenvolvimento como um direito humano é fazer com que este último se torne, ao lado do primeiro, um paradigma e um referencial ético capaz de orientar a ordem internacional, o que já é previsível a partir do intenso positivismo universal relacionado aos direitos humanos, vez que há um grande número de tratados sobre a matéria. Estes elementos normativos não deixam portanto, de ser consequência deste referencial ético compartilhado pelos Estados e pelas organizações internacionais. 


\section{A QUESTÃo DA TITULARIDADE E EFETIVIDADE DO DIREITO AO DESENVOLVIMENTO}

O direito ao desenvolvimento tende a ser considerado como um direito de titularidade mista, mas não pode ser implementadosomente a partir do consenso de vontades individuais (GARCIA-AMADOR, 1997). O que se espera na efetivação do direito ao desenvolvimento é que haja um acordo de vontades individuais e coletivas.

Avaliando-se que desenvolvimento implica ações decorrentes dos Estados, organizações internacionais e sociedade civil, atribuir ao direito ao desenvolvimento titularidade essencialmente individual, na tentativa de preservar a essência teórica dos direitos humanos, é determinar que pode haver a partir de então, apenas melhoria da condição individual, mas não desenvolvimento como um processo.

$\mathrm{O}$ direito ao desenvolvimento pode ser considerado um direito individual em sua origem e em seu fim, mas um direito coletivo em sua implementação, o que ratifica a determinação da Declaração de 1986 ao dispor sobre a pessoa humana como sujeito central e principal destinatário do processo de desenvolvimento e atribuir aos Estados a responsabilidade de formulação de políticas adequadas para o desenvolvimento.

O artigo $1^{0}$ da Declaração sobre o Direito ao Desenvolvimento de 1986 determina que o direito ao desenvolvimento é um direito de todo ser humano e de todos os povos, refletindo assim uma faceta individual e coletiva deste direito, ao estabelecer que o direito ao desenvolvimento é um direito de todo ser humano, dos povos e das nações (Preâmbulo).

É certo que não há identificação específica dos Estados como titulares deste direito, porém no artigo $2^{\circ}, \S 3^{\circ}$, a Declaração estende aos Estados o papel de protagonista no processo de promoção do desenvolvimento. Em nenhum momento a Declaração se afasta da ideia de tomar o indivíduo como sujeito principal e destinatário direito do processo de desenvolvimento. Portanto, a discussão sobre a titularidade acaba por ser superada quando se vinculam os interesses do Estado com os dos indivíduos, e de fato é quase impossível encontrar Estados que deliberadamente não tomem a promoção do desenvolvimento como um de seus objetivos principais, pelo menos do ponto de vista formal.

Quando da formulação e da definição do conceito de direito ao desenvolvimento na esfera internacional, nas décadas de 1970 e 1980 , este foi visto pelos representantes dos países em desenvolvimento como um direito 
exclusivamente coletivo, de titularidade atribuída aos povos e aos Estados. Mas este posicionamento se mostrou contrário à própria dinâmica dos direitos humanos, que não são exclusivamente direitos individuais ou direitos coletivos; podem ser os dois, ao mesmo tempo.

No caso do direito ao desenvolvimento, aquele que detém o direito pode ser uma coletividade, como o Estado, mas o beneficiário direto deve ser o indivíduo; há um relacionamento estreito entre a coletividade e o indivíduo, tanto é que a Comissão de Direitos Humanos das Nações Unidas admite, na Resolução 5, de 02 de março de 1979, e na Resolução 43, de 14 de março de 1985, que o desenvolvimento é uma prerrogativa tanto dos Estados como dos indivíduos.

A opção que leva a considerar o direito ao desenvolvimento como direito de titularidade mista (individual e coletiva) é a que parece mais coerente, já que a igualdade de oportunidades deve ser considerada prerrogativa tanto dos Estados como dos indivíduos (A/RES/70/2626, § 12). Considerar que o direito ao desenvolvimento pode serum direito exclusivamente individual ou exclusivamente coletivo pode ser um equívoco, uma vez que não há porque determinar que os interesses dos indivíduos sejam contrários ou estejam sempre em conflito com os interesses dos Estados.

Sendo assim, pode-se classificar o direito ao desenvolvimento como um direito e interesse difuso, vez que não há determinação dos titulares desse direito de maneira individualizada. Direitos e interesses difusos são caracterizados como direitos que se relacionam a um número indeterminado de pessoas; são direitos de natureza indivisível, vez que não se pode determinar exatamente o titular da prestação jurisdicional devida (MARQUES, 2006, p. 975).

Leite (1996) aposta na indeterminabilidade dos sujeitos como elemento central para atribuir a determinada pretensão a qualificação de interesse difuso, e agrega a essa determinação algumas outras características que são perceptíveis quando se trata da exigibilidade do direito ao desenvolvimento.

Para o autor, os direitos ou interesses difusos, além de serem indivisíveis, admitem pluralidade de sujeitos vinculados por uma circunstância de fato tamanha que chega a se confundir com a comunidade. Outra característica apontada pelo autor que serve para a caracterização do direito ao desenvolvimento como direito difuso é a indivisibilidade ampla, ou seja, "a satisfação de um só implica a satisfação de todos, assim como a lesão de um só constitui a lesão da inteira coletividade" (LEITE, 1996, 
p.33).

O entendimento de Macedo (1996, p. 204) confirma sobremaneira a determinação do direito ao desenvolvimento como direito de terceira dimensão e portanto, como direito difuso:

\begin{abstract}
E por fim, surgiram os direitos difusos ou metaindividuais, chamados de direitos de terceira geração. Podem ser facilmente confundidos com os anteriores por serem também sociais, mas ocorrem algumas distinções. Nasceram em decorrência de determinadas situações, que acabam por prejudicar o ser humano, mas da referida relação não se pode inferir uma ligação imediata entre o interesse e o bem a ser tutelado. Este bem é indivisível. Isto significa que a sua esfera de atuação permeia o campo de liceidade de um só indivíduo (transindividualidade). Disto decorre que o objeto é indisponível, pois satisfaz uma coletividade. Mas não é uma coletividade certa e sim, indeterminada, ligada por uma união de fato. Daí dizer-se que o sujeito é indeterminado.
\end{abstract}

Desta forma, é estendendo ao indivíduo a possibilidade de buscar o direito ao desenvolvimento por meio de procedimentos de alcance coletivo que se favorece $o$ interesse da própria coletividade, portanto dos Estados, que a partir de então são capazes de realizar efetivamente este direito, uma vez que o direito individual implica necessariamente o direito de todos, como expresso no art. 29 da Declaração Universal dos Direitos Humanos.

Em síntese, o direito ao desenvolvimento é um direito dos indivíduos, de toda a humanidade e dos Estados; seu caráter multidimensional em relação à titularidade é reforçado pela Declaração de 1986, quando considera que os aspectos civis, econômicos, sociais, culturais e políticos do desenvolvimento são indivisíveis e complementares. Faz-se, portanto, necessária a revisão das disposições relativas àsrelações internacionais, principalmente de caráter econômico, a fim de considerar o direito ao desenvolvimento como um direito que apenas se efetiva se houver a participação dos Estados, dos indivíduos e da comunidade internacional como um todo.

Além da titularidade, outra questão que diz respeito às pretensões relacionadas com o direito ao desenvolvimento é a problemática da efetivação. Não somente quanto ao direito ao desenvolvimento, mas aos direitos humanos como um todo. Estes direitos podem coexistir como um padrão moral que apesar de não prever sanção legal ou contraprestação imediata, cristaliza-se em um sistema eficiente para o convencimento dos responsáveis em implementá-los (Estados, por exemplo) quanto à necessidade de concessão e previsão destes direitos (SENGUPTA, 1999, p. 77). Reconhecer um direito como direito humano confere à implementação do 
mesmo prioridade ante às instituições nacionais e internacionais, obrigando os Estados e a comunidade internacional.

Com fundamento nestas razões é que se pode admitir que o direito ao desenvolvimento é um direito humano, vez que adotado pela sociedade internacional através por meio consenso, sendo identificados neste processo os responsáveis pela implementação deste direito (os Estados, as agências e instituições nacionais e internacionais, a sociedade civil).

Sengupta (1999, p. 77) não prevê outra classificação para o direito ao desenvolvimento que não como direito humano, e indica ser necessário apenas que programas e procedimentos para a implementação deste direito sejam seguidos pelos responsáveis; afirma que se faz necessária uma base legislativa formal para que o "padrão moral" associado aos direitos humanos e ao direito ao desenvolvimento se torne legalmente obrigatório:

A crítica confunde direitos humanos com direitos legais. Direitos humanos baseiam-se em padrões morais com vistas à dignidade humana, possuindo diversas maneiras de consecução, dependendo da aceitabilidade da base ética das demandas. Isso, é claro, não ofusca a importância da utilidade desses direitos humanos traduzidos em direitos legais sob a legislação. $\mathrm{Na}$ verdade, toda tentativa deveria ser feita no sentido de formular e adotar instrumentos legislativos apropriados para assegurar a realização das demandas de um direito humano, uma vez que seja aceito através do consenso (SENGUPTA, 1999, p 77).

Silva (2004, p. 50) sustenta opinião semelhante à de Sengupta. Para o autor brasileiro, as determinações relativas ao direito ao desenvolvimento em âmbito internacional devem servir como base interpretativa, uma vez que os Estados são os destinatários das normas internacionais. Mesmo que o viés positivo destas normas seja programático, a exigência e a promoção delas se tornam essenciais e indispensáveis.

$\mathrm{Na}$ tentativa de efetivar e garantir o exercício dos direitos humanos e do direito ao desenvolvimento, há ações de âmbito interno capazes de promover o desenvolvimento, principalmente por meio de mudanças institucionais, mas esta tarefa pode tornar-se impossível sem cooperação internacional.

O Centro para o Desenvolvimento e Direitos Humanos, instituição de pesquisa situada em Nova Déli e liderada pelo professor e pesquisador indiano Sengupta, propõe duas maneiras de concretizar ações capazes de promover o desenvolvimento que acabariam por favorecer a coletividade reconhecida como refugiados econômicos (2004, p. 64): por meio de processos multilaterais de cooperação, em que os países desenvolvidos, as organizações internacionais e as 
instituições de caráter privado podem promover em conjunto ações que favoreçam a qualificaçãoinstitucional dos países em desenvolvimento ou por meio de ações bilaterais específicas, de país a país, que também promovem a qualificação institucional ou colaboram para a realização do direito ao desenvolvimento a partir de ações direcionadas aos componentes desse direito.

Em caráter internacional, algumas questões apontadas por PerroneMoisés (1999, p. 191) devem ser consideradas: i) o desenvolvimento dos Estados depende sobremaneira da sociedade internacional; ii) a interdependência leva não somente a aproximação de vantagens econômicas como à aproximação dos problemas ligados ao desenvolvimento; eiii) o desenvolvimento em escala internacional enfrenta problemas ligados às relações econômicas desvantajosas e exclusivistas.

Uma vez que não há uma definição direta sobre o papel das organizações da iniciativa privada na promoção do desenvolvimento, Perrone-Moisés (1999, p. 181194) entende ser necessário estabelecer normas tanto no plano interno como no plano internacional a fim de se combater excessos econômicos vinculados à concentração de riqueza e quanto à restrição do acesso ao mercado internacional. As regras deveriam ser propostas no sentido de corrigir deficiências e falhas de mercado, considerando-se essencial também a transparência nas relações econômicas internacionais.

A cooperação internacional necessária para enfrentar a questão do desenvolvimento pode ser considerada por meio da formulação de um contrato internacional pactuado entre Estados e demais atores da sociedade internacional, que toma forma a partir de um modelo jurídico derivado do direito anglo-saxão denominado partnership. Seria um contrato flexível, a partir do qual se estabelece uma parceria não apenas entre Estados e organizações internacionais intergovernamentais, mas também com organizações não governamentais, sociedades privadas nacionais, associações de classe e outros grupos (GARCIAAMADOR, 1997).

Internamente, a primeira questão que se pode levantar é a das políticas nacionais de desenvolvimento que via de regrasão estabelecidas pelas instituições financeiras internacionais e pelos países desenvolvidos. Porém, tais estratégias podem incorrer em erro ao desconsiderar particularidades locais e regionais. Ao aproximar políticas de desenvolvimento da perspectiva dos direitos humanos, há que 
se considerar o direito à autodeterminação dos povos, considerando-se que não há um único modelo de sucesso a ser seguido (PERRONE-MOISÉS, 1999, p. 190). Cada país é soberano para determinar o seu modo de produção e regime econômico, como estabelece o art. $1^{\mathrm{o}}$ do Pacto dos Direitos Econômicos, Sociais e Culturais.

A relação entre direito ao desenvolvimento e os refugiados econômicos é clara. Estas pessoas deixam seus países em busca da garantia e efetivação de direitos humanos essenciais. Não se trata apenas da busca por melhor qualidade de vida.

Os refugiados econômicos não têm escolha no país de origem. Daí a procura por um lugar onde condições mínimas de sobrevivência lhe sejam asseguradas, vez que em suas localidades de origem não têm sequer direito à alimentação, trabalho e moradia dignos. Sendo assim o direito ao desenvolvimento é uma necessidade a ser efetivada e que merece proteção internacional. Considerando estas questões é que se associa a busca dos refugiados econômicos à busca pela efetivação do direito ao desenvolvimento.

\section{CONSIDERAÇÕES FINAIS}

De há muito se sabe que a grande questão junto aos sistemas nacionais e internacionais de direitos humanos não é a positivação deles ou mesmo o seu reconhecimento, mas sim a sua garantia e efetivação. E é neste cenário de busca pela concretização dos direitos humanos que se encontram os refugiados econômicos e sua relação com o direito ao desenvolvimento.

Embora não reconhecidos como categoria formal de refugiados, e desta forma desprotegidos pelas determinações da Convenção de 1951, os chamados refugiados econômicos - pessoas que deixam seus países de origem não apenas em busca de melhores condições de vida, mas sim em busca da efetivação de suas necessidades mais básicas como ser humano - não podem nem ser deixados à margem do arcabouço de proteção garantido à pessoa humana, ainda que a primeira responsabilidade seja de seus Estados de origem, tal seja estabelecer políticas públicas e ações positivas no intuito de garantir aos seus cidadãos condições de sobrevivência digna.

Definir o alcance da expressão refugiados econômicos é por si só uma questão delicada, vez que não são considerados refugiados em sentido clássico e nem migrantes comuns, pois lhes falta o elemento volitivo que caracteriza as migrações em sentido amplo. Enquanto o migrante deixa seu país de origem apenas em busca 
de melhores condições de vida, o refugiado deixa seu Estado por uma questão de sobrevivência.

Considerando este fato, há meios de estender aos refugiados econômicos proteção internacional diferenciada da destinada aos refugiados em sentido clássico. Mesmo não havendo o bem fundado temor de perseguição ou as obrigações formalmente assumidas pelos Estados signatários da Convenção de 51, os Estados assumiram junto ao sistema internacional de proteção dos direitos humanos obrigações outras que dizem respeito a todos que estejam sob seus territórios.

O que buscam, pois, os refugiados econômicos é, em síntese, representado pelo direito ao desenvolvimento. Considerado direito humano desde a Declaração sobre o Direito ao Desenvolvimento de 1986, o direito ao desenvolvimento faz parte de um conjunto de obrigações e deveres assumidos pelos Estados junto à sociedade internacional.

É fato que a garantia e a efetivação do direito ao desenvolvimento perpassa por uma série de questões delicadas e mesmo difíceis, desde o simples reconhecimento deste direito até as medidas necessárias para a efetivação do mesmo. De início, pode-se questionar como se pleiteia este direito, ou quem pode fazê-lo, vez que a titularidade do direito ao desenvolvimento não é simplesmente resolvida e parece estranho que o indivíduo vá até uma corte internacional litigar em busca de "seu" direito ao desenvolvimento. Considerando este fato é que se estabelece a titularidade coletiva deste direito, podendo ser enquadrado como um dever e uma obrigação do Estado, por meio de prestações positivas, bem como um compromisso internacional assumido quando o ente estatal reconhece a indissociabilidade dos direitos humanos.

Sabe-se que a problemática da efetivação dos direitos humanos é tema de longas discussões e que se está longe da garantia deles de maneira satisfatória, mas nem por isso os estados podem ignorar as pretensões neste sentido, seja de seus nacionais seja de estrangeiros.

\section{REFERÊNCIAS}

APOLINARIO, Silvia MenicucciO.S.;JUBILUT, Liliana Lyra. A necessidade de proteção internacional no âmbito da migração. Revista Direito GV. n. 11, jan-jun. 2010. p. 275-294

BARRAL, Welber (Org.). Direito e desenvolvimento: análise da ordem jurídica brasileira sob a ótica do desenvolvimento. São Paulo: Singular, 2005 
CASELLA, Paulo Borba. Refugiados: conceito e extensão. In: ARAUJO, Nadia de; ALMEIDA, Guilherme de Assis. O Direito Internacional dos Refugiados: uma perspectiva brasileira. Rio de Janeiro: Renovar, 2001. p. 17-27

CUNHA, Ana Paula. O Direito Internacional dos Refugiados em cheque: refugiados ambientais e econômicos. Revista Brasileira de Direito Internacional. v. 8, n. 8, jul-dez, 2008. p. 177-201

DELGADO, Ana Paula Teixeira. O direito ao desenvolvimento na perspectiva da globalização: paradoxos e desafios. Rio de Janeiro: Renovar, 2001

FELLER, Erika. A Convenção para Refugiados, aos 6o anos: ainda adequada a seu propósito? Cadernos de Debates: refúgio, migrações e cidadania. v.6, n. 6, 2011. Brasília: Instituto Migrações e Direitos Humanos. p. 13-32

FRIED, Jonathan $T$. International economic law and financing development: The Monterrey Consensus and beyond. XXXI Session of the Summer Course on International Law of the Inter-American Juridical Commmittee.Rio de Janeiro, Brazil, August 2004

GARCIA-AMADOR, F. V..Elderecho internacional del desarrollo: uma nueva dimension del Derecho Internacional Económico. Madrid: Civitas, 1987

LOCATELLI, Liliana. Desenvolvimento na Constituição Federal de 1988. In: BARRAL, Welber (Org.). Direito e desenvolvimento: análise da ordem jurídica brasileira sob a ótica do desenvolvimento. São Paulo: Singular, 2005. p. 95-118

MACEDO, Paulo Emílio Vauthier Borges de. O papel das associações civis na defesa dos interesses difusos. In: OLIVEIRA JÚNIOR, José Alcebíades de;

MORATO LEITE, José Rubens (Orgs.). Cidadania coletiva. Florianópolis: Paralelo 27, 1996. p. 201-214

MARQUES, Claudia Lima; BENJAMIN, Antônio Herman V; MIRAGEM, Bruno. Comentários ao Código de Defesa do Consumidor. 2.ed. rev. atual. ampl. São Paulo: Revista dos Tribunais, 2006

MORATO LEITE, José Rubens. Interesses meta-individuais: conceitos, fundamentações e possibilidade de tutela. In: OLIVEIRA JÚNIOR, José Alcebíades de; MORATO LEITE, José Rubens (Orgs.). Cidadania coletiva. Florianópolis: Paralelo 27, 1996. p. 27-44

PERRONE-MOISÉS, Cláudia. Direito ao desenvolvimento e investimentos estrangeiros. São Paulo: Oliveira Mendes, 1998

SACHS, Jeffrey D..The end of poverty: how we can make it happen in our lifetime. London: Penguin Books, 2005.

SENGUPTA, Arjun. The right to development as a human right. FrançoisXavier Bagnoud Center for Health and Human Rights, Harvard School of Public Health, 1999. Disponível em: <http://www.hsph.harvard.edu/fxbcenter/FXBC_WP7--Sengupta.pdf>. Acesso em: dez. 2004

SILVA, Guilherme Amorim Campos da. Direito ao desenvolvimento. São Paulo: Método, 2004 
TRUBEK, David. Economic, social and cultural rights in the Third World: human rights law and human needs programms. In: MERON, Theodor (Ed.). Human rights in International Law: legal and policy issues. Oxford: Claredon Press, 1984 UNDP.Protecting and promoting the universal values of human rights and the rule of law. Disponível em: <http://www.undp.org/democraticgovernance>. Acesso em: jul. 2007

WORLD BANK. Development and human rights: the role of the World Bank. Washington, DC: The International Bank for Reconstruction and Development/The World Bank, 1998. 